Article

\title{
Enhancement of Neuroprotective Effects of Spirulina platensis Extract from a High-Pressure Homogenization Process
}

\author{
Woon Yong Choi ${ }^{1}$ and Hyeon Yong Lee ${ }^{2, *}$ \\ 1 Department of Medical Biomaterials Engineering, Kangwon National University, \\ Chuncheon 200-701, Korea; cwy1012@hanmail.net \\ 2 Department of Food Science and Engineering, Seowon University, Cheongju 361-742, Korea \\ * Correspondence: hyeonl@seowon.ac.kr; Tel.: +82-43-299-8471
}

Received: 16 March 2018; Accepted: 17 April 2018; Published: 19 April 2018

Featured Application: This non-thermal process could be applied to extract heat sensitive natural resources.

\begin{abstract}
This study is the first to show that a simple high-pressure homogenization process (HP) could extract very heat-sensitive chlorophyll from a marine alga, Spirulina platensis. Up to $9.85 \mathrm{mg} / \mathrm{g}$ was produced at an optimal input pressure of 650 bar with a shear stress of approximately 20,000 $(1 / \mathrm{s})$ compared to $5.27 \mathrm{mg} / \mathrm{g}$ from conventional $70 \%$ ethanol extraction (EE) at $40{ }^{\circ} \mathrm{C}$ for $24 \mathrm{~h}$. However, a higher input pressure did not increase the extraction yield and in fact decreased it, possibly due to the destruction of chlorophyll $a$ at a high shear stress of approximately 50,000 (1/s) under 1370 bar of input pressure. Chlorophyll $a$ and other components of the extract had additive effects, showing higher antioxidant activities of ca. $56 \%$ of DPPH radical scavenging activities than $10 \mu \mathrm{g} / \mathrm{mL}$ chlorophyll $a$ alone, which corresponded to the same chlorophyll $a$ content that existed in the extract. It was also confirmed that the high antioxidant activities of the HP extract reduced the production of reactive oxygen species (ROS) from glutamate-induced HT22 cells, which resulted in increased neuroprotective activity compared to EE and even chlorophyll $a$ alone, in addition to effectively reducing the release of $\mathrm{Ca}^{2+}$ from nerve cells.
\end{abstract}

Keywords: Spirulna platnesis; high pressure homogenization; neuroprotective activities

\section{Introduction}

Spirulina, commonly called 'space food', which has been used for astronauts in National Aeronautics and Space Administration (NASA) projects [1], is considered a high-quality food and/or dietary supplement for humans because it contains large amounts of high-quality protein and many lipids and bioactive substances [2,3]. Therefore, Spirulina has been studied mostly to investigate its biological activity and to develop processing technologies to upgrade its quality. However, to date, most Spirulina consumed worldwide has been in the form of simple dried powders in spite of their unpalatable flavors, as most bioactive components of Spirulina, such as C-phycocyanin (C-PC), xanthophylls, and chlorophylls, are extremely unstable and especially susceptible to heat $[4,5]$. That is why, in processing Spirulina, minimal heat should be applied; however, the use of less heat to process natural resources that contain Spirulina inevitably reduces the production yield as well as the biological activity of the products. Therefore, several low-heat extraction processes have been introduced for Spirulina, such as processes with simple and/or combined ultrasonic extraction, enzymatic hydrolysis, and various extraction solvents, which are carried out strictly at low temperatures [6,7]. In extracting various bioactive components of Spirulina by employing the above technologies, C-PC and chlorophylls 
are most often the focus, since Spirulina sp. is known to contain fairly high amounts of C-PC compared to many other microalgae. Chlorophyll and C-PC have many biological effects, such as anti-cancer, anti-aging, anti-inflammatory and antioxidant activity effects [8,9]. Additionally, Spirulina provides the pure intact form of chlorophyll $a$ at the lowest production costs, since most of the chlorophyll (approximately 90\%) that exists in Spirulina is in the form of chlorophyll $a[10,11]$. In particular, the demand for chlorophyll $a$ has recently increased because its biological activity, such as antioxidant activity, is considered to be higher than that of other chlorophylls, such as chlorophyll $b$ or $c$ [12]. However, the abundant chlorophyll in plants is a mixture of chlorophyll $a, b$, and $c$, which would increase the cost of extracting and purifying chlorophyll $a$ from plant sources.

Therefore, in this work, to obtain high amounts of heat-labile chlorophyll a from Spirulina, we developed a unique low-temperature extraction process employing high-pressure homogenization (HP). The ultrasonic extraction process has several disadvantages when scaled up, and in general, it requires the installation of more equipment than is required for conventional solvent extraction processes with water, ethanol, or other substances. Ultrasonic extraction also needs to be combined with other processes, although it has been shown to be effective in processing natural products at a low temperature $[13,14]$. In general, HP has been used mostly for mixing hydrophobic and hydrophilic components in solution for the cosmetic and food industries by applying a high input pressure of 10,000-30,000 psi, and this process was shown to be more effective than a simple mixing process [15]. In addition to the original application of HP, in this work, the HP process was applied to extract chlorophyll $a$ from Spirulina at room temperature in a very short period of time, i.e., 5-10 min, since the process can easily break down the hard cell walls by applying a high shear stress only to the cells that pass through a very small orifice, approximately $70 \mu \mathrm{m}$ in diameter, with a high pressure of 10,000-30,000 psi [16,17]. Very high shear forces can easily destroy the cell membranes of Spirulina and consequently release chlorophyll $a$ into the extraction solution without any additional effort. Thus, the extracts from this process contain large amounts of intact chlorophyll $a$. This chlorophyll $a$ content is expected to enhance the biological activity of the extracts from the high-pressure homogenization process compared to those from conventional extraction processes, i.e., $70 \%$ ethanol extraction at $40{ }^{\circ} \mathrm{C}$, and perform even better than ultrasonic extraction. In this work, in addition to the extraction yields of chlorophyll $a$ by HP, the extracts will also be compared with those from other processes in terms of neuroprotective activity, since these results can be applied to expand the use of Spirulina extracts, which may mean people will not need to ingest the whole cell powder.

\section{Materials and Methods}

\subsection{Preparation of the Samples}

First, for the control process of $70 \%$ ethanol extraction (EE), $100 \mathrm{~g}$ of dried Spirulina platensis powder (Pure Hawaiian Spirulina Pacifica ${ }^{\circledR}$, Nutrex, Kailua, HI, USA) was extracted in a 1 L reflux extractor with $1 \mathrm{~L}$ of $70 \%$ ethanol at $40{ }^{\circ} \mathrm{C}$ for $24 \mathrm{~h}$. Then, the extract was concentrated with a rotary vacuum evaporator (Rotary Vacuum Evaporator N-N series, EYELA, Rikakikai Co., Tokyo, Japan) and freeze dried with a lyophilizer (PVTFA 10AT, ILSIN, Suwon, Korea). For high-pressure homogenization extraction (HP), $100 \mathrm{~g}$ of dried S. platensis was first mixed with $1 \mathrm{~L}$ of $70 \%$ ethanol, and the mixture was fed into a high-pressure homogenizer with a Y-type cell that had an orifice approximately $70 \mu \mathrm{m}$ in diameter through which to pass the samples (high-pressure processor; MN400BF; PiCOMAX, Seoul, Korea) under various input pressures from 350 bar to 1500 bar. Then, the extracts that passed through under each input pressure were collected from the outlet of the homogenizer, and the extract was also concentrated and freeze dried by the same procedure used to prepare the EE. The powders from each process were stored at $-20{ }^{\circ} \mathrm{C}$ before use. In addition to preparing the extracts, we observed the structural changes in Spirulina before and after passing through a high-pressure homogenizer and imaged both stages with a scanning electron microscope (SEM, XL 30, Philips, Amsterdam, The Netherlands) as follows [18]: The sample slices were washed three times for 2 min each using 
$0.05 \mathrm{M}$ sodium cacodylate buffer ( $\mathrm{pH} 7.2$ ), fixed with $1 \%$ osmium tetroxide solution for $2 \mathrm{~h}$ at $4{ }^{\circ} \mathrm{C}$, and washed two times with tertiary distilled water at room temperature. The fixed samples were dehydrated in 30\%, 50\%, 70\%, 80\%, and 90\% ethanol for $10 \mathrm{~min}$ each and in $100 \%$ ethanol three times for 10 min each. After dehydration, the samples were mounted on metal stubs for two periods of transition for $15 \mathrm{~min}$ each using $100 \%$ propylene oxide, coated with gold using a sputter coater (Agar Scientific Ltd., Essex, UK), and observed with a scanning electron microscope (SEM, Philips XL30E, Danville, KY, USA).

\subsection{Determination of the Chlorophyll a Content of the Extracts}

High-performance liquid chromatography (HPLC, 500 Series, BIO-TEK, Milan, Italy) with a C18 column $(4.6 \times 250 \mathrm{~mm}, 5 \mu \mathrm{m}$, Jupiter, Phenomenex, Torrance, CA, USA $)$ was used to measure the amounts of chlorophyll $a$ in the extracts from each extraction process as follows [19]: acetonitrile:methanol:ethyl acetate (6:2:2) was used as the mobile phase under isocratic conditions at a flow rate of $1 \mathrm{~mL} / \mathrm{min}$ for $20 \mathrm{~min}$, and measurements were taken at $420 \mathrm{~nm}$ with a UV detector (BIO-TECK) against a chlorophyll $a$ standard (CAS\#479-61, Research Chemicals, Toronto, ON, Canada).

\subsection{Measurement of Antioxidant Activity of the Extracts}

DPPH ( $\alpha, \alpha$-diphenyl- $\beta$-picrylhydrazyl) radical scavenging activity was measured as an indicator of the antioxidant activity of the extracts [20], as follows: $150 \mu \mathrm{L}$ of $0.1 \mathrm{mM}$ DPPH solution in an ethanol solvent was mixed with $150 \mu \mathrm{L}$ of $S$. platensis extract at a concentration adjusted to $0.1,0.5$, or $1.0 \mathrm{mg} / \mathrm{mL}$ or $10 \mu \mathrm{g} / \mathrm{mL}$ of chlorophyll $a$ as a positive control in each well of a 96-well plate. The 96-well plate was then left unattended for $20 \mathrm{~min}$ in a dark room at $25^{\circ} \mathrm{C}$, and the optical density (O.D.) of each mixture was measured at a wavelength of $525 \mathrm{~nm}$ using the following Equation (1).

$$
\text { DPPH radical scavenging activity }(\%)=(\text { Control O.D. }- \text { Sample O.D. }) /(\text { Control O.D. }) \times 100
$$

\subsection{Measurement of Neuroprotective Activity of the Extracts}

To observe the neuroprotective activities of the extracts, a 3-(4,5-dimethylthiazol-2-yl)-2,5 -diphenyltetrazolium bromide (MTT) assay method was used as follows [21]: First, cells from the HT22 mouse hippocampal cell line (ATCC, Manassas, VA, USA) were inoculated into a well of a 96-well plate at $1.5 \times 10^{4}$ cells/well. The cells were divided into an experimental group treated with glutamate and another experimental group that was not treated with glutamate. After $200 \mu \mathrm{L}$ of S. platensis extract at each concentration or $1 \mu \mathrm{g} / \mathrm{mL}$ of chlorophyll $a$ as a positive control was added to the cells, the cells were cultured for $24 \mathrm{~h}$ in a $\mathrm{CO}_{2}$ incubator. Subsequently, an MTT solution at a concentration of $5 \mu \mathrm{g} / \mathrm{mL}$ was added to each well, and the supernatant was removed after $4 \mathrm{~h}$. Finally, $10 \mu \mathrm{L}$ of acid-isopropanol solution $(0.04 \mathrm{~N} \mathrm{HCl}$ in isopropanol) was added to the solution to complete the reaction. The final absorbance of the solution was measured at $565 \mathrm{~nm}$ using a microplate reader (Tecan, San Jose, CA, USA). To confirm the neuroprotective effects associated with the antioxidant activity of the extracts, we measured the decrease in reactive oxygen species (ROS) production by HT22 cells by applying various concentrations of the extracts, as follows [21]: HT22 cells were plated in a 48 -well plate at $1.5 \times 10^{4}$ cells / well and incubated at $37^{\circ} \mathrm{C}$ for $24 \mathrm{~h}$. After the cell cultures were established, each $S$. platensis extract sample and $10 \mu \mathrm{L}$ of glutamate were added and further incubated for $8 \mathrm{~h}$. As positive controls, $1 \mu \mathrm{M}$ Trolox and $1 \mu \mathrm{g} / \mathrm{mL}$ chlorophyll $a$ were administered. Then, $10 \mu \mathrm{M}$ of $2^{\prime}, 7^{\prime}$-dichlorofluorescin diacetate (DCF-DA) was added to each well and incubated for $1 \mathrm{~h}$. Finally, $1 \%$ Triton X-100 was added to each well, and the solutions were measured at wavelengths of $488 \mathrm{~nm}$ and $530 \mathrm{~nm}$. In addition to the measurement of ROS production, the production of $\mathrm{Ca}^{2+}$ ions by HT22 cells was measured as follows [22]: Calcium ion $\left(\mathrm{Ca}^{2+}\right)$ release from HT22 cells was measured using Fura-2AM. Before the cells were harvested, each sample was treated with Trolox (positive control) and glutamate followed by the addition of $2 \mu \mathrm{M}$ Fura-2AM. After $2 \mathrm{~h}$, the cells were washed with PBS and 
treated with $1 \%$ Triton $\mathrm{X}-100$. Calcium ions $\left(\mathrm{Ca}^{2+}\right)$ were measured using a fluorescence analyzer at an excitation wavelength of $400 \mathrm{~nm}$ and an emission wavelength of $535 \mathrm{~nm}$.

\subsection{Statistical Analysis}

All of the experiments were carried out at least three times and are shown as the mean \pm SEM (standard error of the mean). A Student's $t$-test and one-way analysis of variance (ANOVA) were performed with the Statistical Analysis System (SAS, Cary, NC, USA), and the significance level was set to $p<0.05, p<0.01$, and $p<0.001$.

\section{Results}

\subsection{Comparison of Chlorophyll a Contents of Extracts and Morphology of Spirulina with and without} High-Pressure Homogenization

Figure 1 shows the chromatograms constructed by analyzing two extracts against a chlorophyll $a$ standard by HPLC. The amounts of chlorophyll $a$ in the extracts from the conventional ethanol extraction and high-pressure homogenization with various input pressures were also compared and are shown in Table 1. The extract with the highest content of chlorophyll $a$, at $9.85 \mathrm{mg} / \mathrm{g}$, was the extract processed at 690 bar with a shear stress of approximately 20,000 (1/s) applied in passing through an orifice of $70 \mu \mathrm{m}$ diameter at a flow rate of $150 \mathrm{~cm}^{3} / \mathrm{min}$ at room temperature (HP-2).

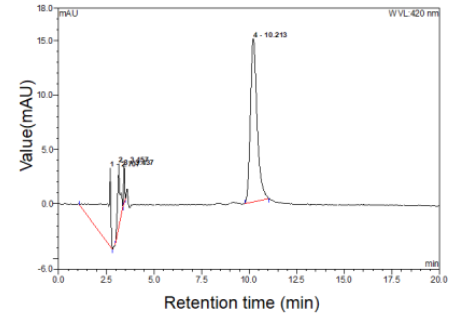

(a)

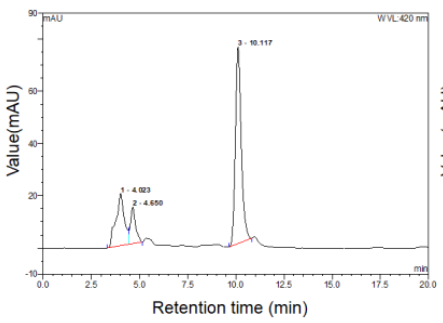

(b)

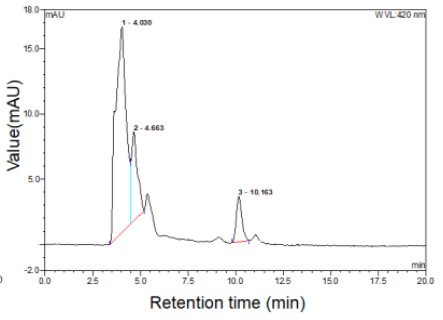

(c)

Figure 1. Comparison of HPLC chromatograms of chlorophyll $a$ from different extraction conditions: (a) Standard chlorophyll $a$; (b) High-pressure homogenization at 690 bar and room temperature; (c) $70 \%$ ethanol extraction at $40^{\circ} \mathrm{C}$ for $24 \mathrm{~h}$.

Interestingly, however, the extract processed at the high pressure of 1370 bar with the very high shear stress of approximately 50,000 (1/s) (HP-3) contained $6.32 \mathrm{mg} / \mathrm{g}$ of chlorophyll $a$, which was much lower than the $9.85 \mathrm{mg} / \mathrm{g}$ obtained with HP-2 at 690 bar. At a lower input pressure of $350 \mathrm{bar}$ (HP-1), the extract had only $4.24 \mathrm{mg} / \mathrm{g}$ of chlorophyll $a$, which was also lower than the yield from the conventional process.

Table 1. Estimation of chlorophyll $a$ contents from Spirulina platnesis in the extracts from various extraction conditions.

\begin{tabular}{cc}
\hline Extraction Process & Chlorophyll $a$ Contents (mg/g) \\
\hline EE $^{1}$ & $5.27 \pm 1.73$ \\
$\mathrm{HP}^{2}{ }^{2}$ & $4.24 \pm 2.61^{*}$ \\
$\mathrm{HP}^{3}$ & $9.85 \pm 1.41^{* * *}$ \\
$\mathrm{HP}^{4}{ }^{4}$ & $6.32 \pm 3.09^{*}$
\end{tabular}

${ }^{1} \mathrm{EE}$ : conventional $70 \%$ ethanol extraction at $40{ }^{\circ} \mathrm{C}$ for $24 \mathrm{~h} .{ }^{2} \mathrm{HP}-1$ : high-pressure homogenization at 350 bar and room temperature. ${ }^{3} \mathrm{HP}-2$ : high-pressure homogenization at 690 bar and room temperature. ${ }^{4} \mathrm{HP}-3$ : high-pressure homogenization at 1370 bar and room temperature. Values are presented as means $\pm \mathrm{SD} ;{ }^{*} p<0.05$, and ${ }^{* * *} p<0.001$ compared with the EE.

Additionally, the electron micrographs of Spirulina support the above results and the hypothesis by illustrating the structural changes in Spirulina before (a) and after (b, c, and d) homogenization 
under pressures of 350, 690, and 1370 bar, respectively. In contrast to untreated Spirulina (Figure 2a), most Spirulina in Figure 2c had their cell walls substantially disrupted after being processed at 690 bar; however, 350 bar of input pressure was not sufficient to break all of the membranes and cell walls of Spirulina (Figure 2b).

(a)

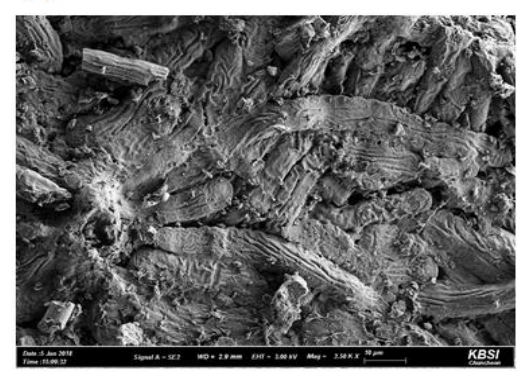

(c)

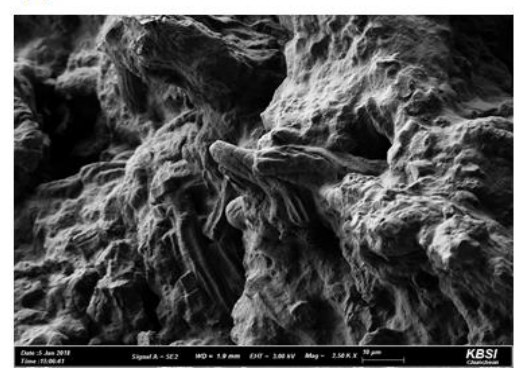

(b)

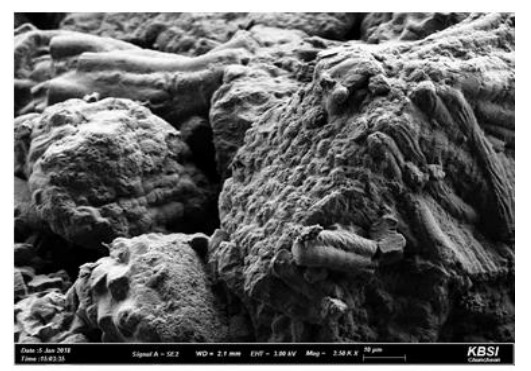

(d)

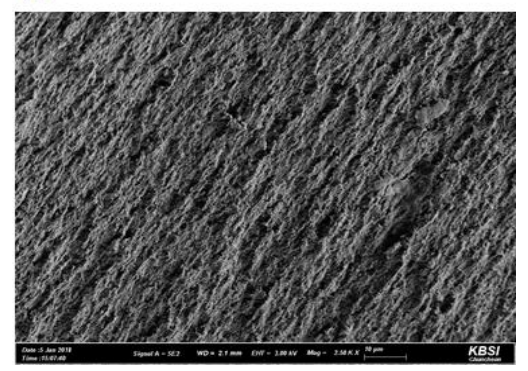

Figure 2. SEM images of Spirulina platensis through a high-pressure homogenization under various input pressures: (a) control (with no treatment); (b) 350 bar; (c) 690 bar; (d) 1370 bar.

Consequently, the yield of chlorophyll $a$ from extraction at 350 bar was lower than the yields from extraction at 670 and 1370 bar and even from conventional 70\% EE as shown in Table 1. However, Figure 2d illustrates that, at 1370 bar, which was the highest pressure, most of the cell membranes and other organs within the cells were completely destroyed, which suggests that intact chlorophyll $a$ within the cells was degraded as well due to a very high shear stress at a high input pressure.

\subsection{Measurement of Antioxidant Effects of the Extracts Using Two Different Extraction Processes}

As shown in Table 1 and Figures 1 and 2, high-pressure homogenization was shown to be an effective nonthermal process for obtaining intact chlorophyll $a$ from Spirulina. To confirm the high quality of the extract from this process, which contained very high amounts of chlorophyll $a$, the neuroprotective activity of HP extract was compared to that of the conventional ethanol extract as well as the efficacy of chlorophyll $a$ itself as a positive control.

Figure 3 compares the antioxidant activity of the extracts from two different processes and chlorophyll $a$ alone, since chlorophyll $a$ is known to have very strong antioxidant activity and the neuroprotective effects of products are known to be closely correlated with antioxidant activity [12,23]. The HP extract showed strong antioxidant effects, with 56\% DPPH scavenging activity, exceeding the effects of the ethanol extract. The activity of the HP extract was even higher than the $42.11 \% \mathrm{DPPH}$ scavenging activity of $10 \mu \mathrm{g} / \mathrm{mL}$ chlorophyll $a$, which was the same chlorophyll $a$ concentration found in HP-2 as estimated in Table 1.

\subsection{Neuroprotective Activities of the Extracts from Different Extraction Processes}

Figure 4 compares the effects of extracts taken by two different methods (EE and HP) and a chlorophyll $a$ positive control in terms of protecting glutamate-treated HT22 cells from neuronal damage. Analogously to the antioxidant activity of the extracts, HP showed the highest neuroprotection, 
with $89.38 \%$ nerve cell survival compared to $78.47 \%$ with $100 \mu \mathrm{g} / \mathrm{mL}$ of the EE product, even exceeding the effect of $1 \mu \mathrm{g} / \mathrm{mL}$ chlorophyll $a$, which is the same concentration that existed in the HP extract. These results also strongly indicated that chlorophyll $a$ must play an important role in protecting cell growth against damage by glutamate, since the HP product contained higher amounts of chlorophyll $a$ than that of EE.

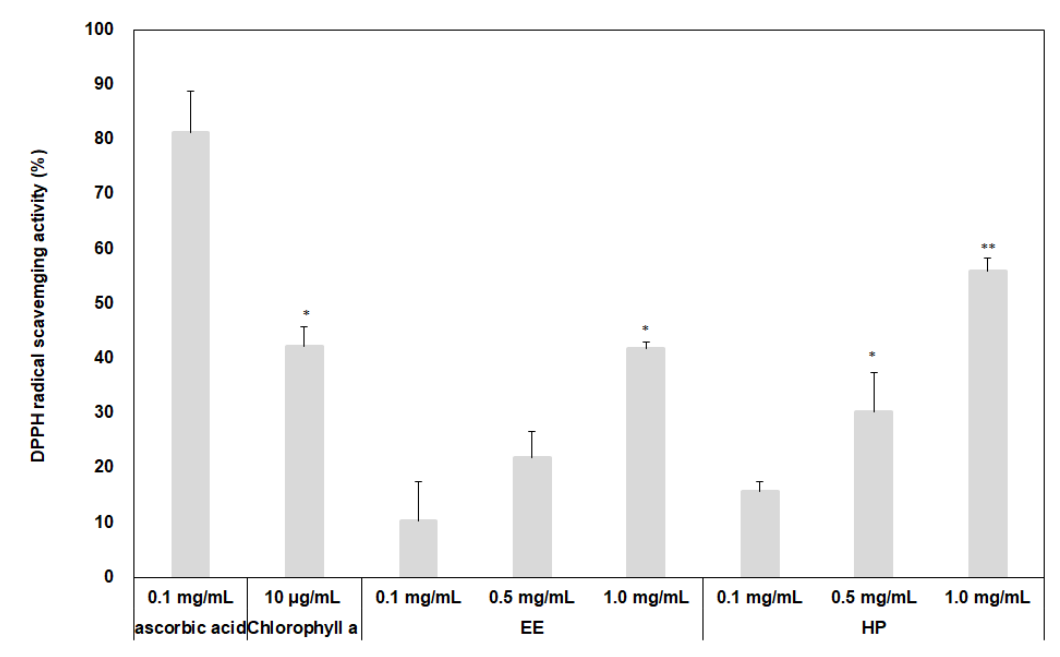

Figure 3. DPPH radical scavenging activities of the extracts from two different processes: 70\% ethanol extraction at $40{ }^{\circ} \mathrm{C}$ for $24 \mathrm{~h}$ (EE) and high-pressure homogenization at 650 bar and room temperature (HP). Values are presented as means $\pm \mathrm{SD} ;{ }^{*} p<0.05$, and ${ }^{* *} p<0.01$ compared with the group of treating ascorbic acid.

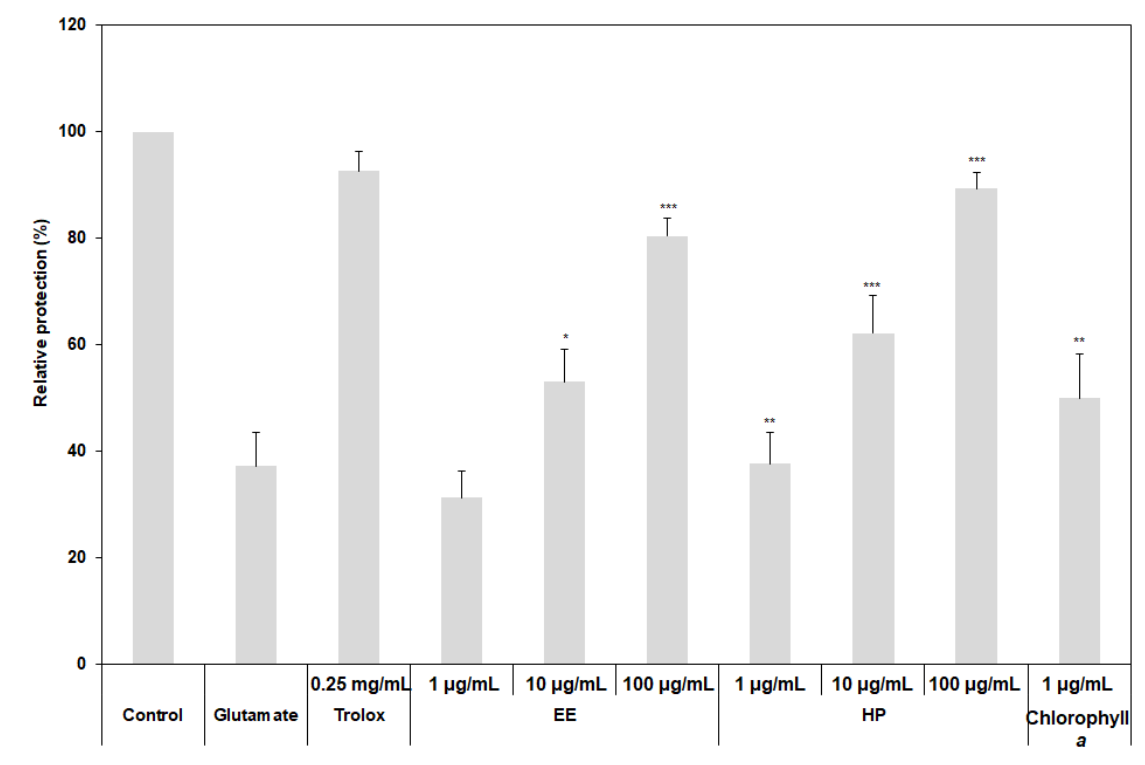

Figure 4. Neuroprotective effects of the extracts on the growth of glutamate-induced HT22 cells: $70 \%$ ethanol extraction at $40{ }^{\circ} \mathrm{C}$ for $24 \mathrm{~h}$ (EE) and high-pressure homogenization at 650 bar and room temperature (HP). Values are presented as means $\pm \mathrm{SD} ;{ }^{*} p<0.05,{ }^{* *} p<0.01$, and ${ }^{* * *} p<0.001$ compared with the group of treating glutamate.

\subsection{Inhibition of Oxidative Stress on HT22 Cells by the Extracts}

To more clearly demonstrate the neuroprotective effects of the HP extract, Figure 5 shows a comparison of ROS production by glutamate-exposed HT22 cells treated with HP extract, ethanol extract, or chlorophyll $a$. 


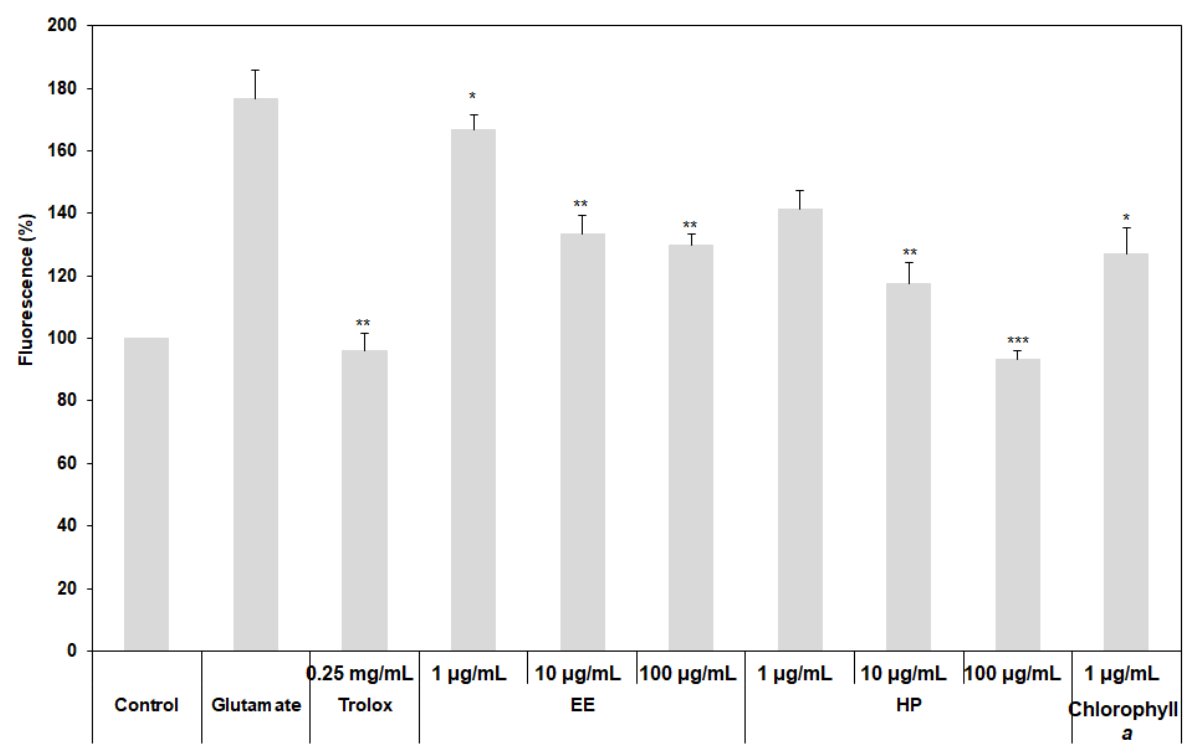

Figure 5. Reduction of reactive oxygen species (ROS) production from glutamate-induced HT22 cells treated by the extracts: $70 \%$ ethanol extraction at $40{ }^{\circ} \mathrm{C}$ for $24 \mathrm{~h}(\mathrm{EE})$ and high-pressure homogenization at 650 bar and room temperature (HP). Values are presented as means $\pm \mathrm{SD}{ }^{*} p<0.05,{ }^{* *} p<0.01$, and ${ }^{* * *} p<0.001$ compared with the group of treating glutamate.

Again, the HP extract showed higher inhibition of ROS production than the EE product or chlorophyll $a$ alone. The data in Figure 6 also confirm that the HP extract decreased the release of $\mathrm{Ca}^{2+}$ from glutamate-exposed mouse hippocampal neuronal cells and that it inhibited oxidative stress as shown in Figure 5. In general, the HP product consistently showed the highest mitigating effect on the release of $\mathrm{Ca}^{2+}$ ions, which exceeded the effects of the EE product and chlorophyll $a$. For most neuroprotective activities, $1 \mu \mathrm{g} / \mathrm{mL}$ of chlorophyll $a$ was shown to have relatively better efficacy than the ethanol extract, and its activity was also found to be greater than that of other chlorophylls, such as chlorophyll $b$ or $c$ from plant sources [24].

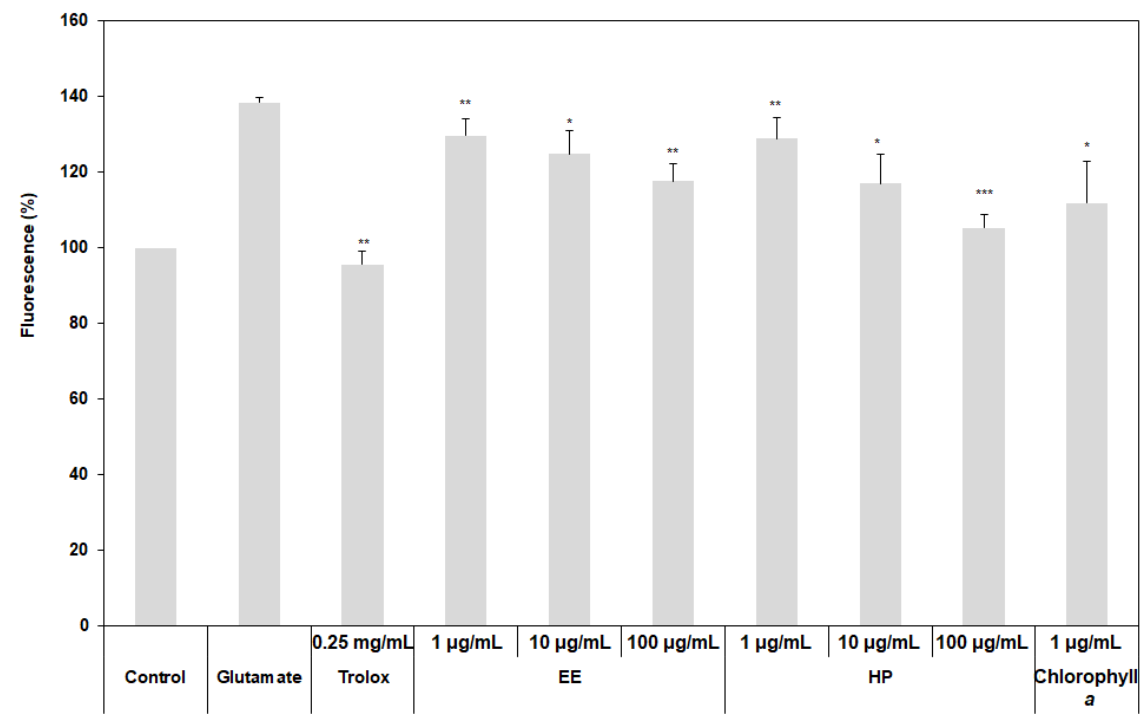

Figure 6. Comparison of the levels of $\mathrm{Ca}^{2+}$ in glutamate-induced HT22 cells treated with the extracts and chlorophyll $a$ : $70 \%$ ethanol extraction at $40{ }^{\circ} \mathrm{C}$ for $24 \mathrm{~h}$ (EE) and high-pressure homogenization at 650 bar and room temperature (HP). Values are presented as means $\pm \mathrm{SD} ;{ }^{*} p<0.05,{ }^{* *} p<0.01$, and *** $p<0.001$ compared with the group of treating glutamate. 


\section{Discussion}

The HPLC peak intensity and areas clearly showed that the high-pressure homogenization process at 690 bar yielded substantial amounts of intact chlorophyll $a$, which was identified by its retention time compared to a standard, while the ethanol extract had very small peak areas. The concentration of chlorophyll $a$ achieved by HP was very high compared to the results from other works, which ranged from $1.2 \mathrm{mg} / \mathrm{g}$ to $9.3 \mathrm{mg} / \mathrm{g}$ chlorophyll $a$ under various extraction conditions [4, $7,25]$ and, in particular, was much higher than the $5.27 \mathrm{mg} / \mathrm{g}$ achieved by conventional $70 \% \mathrm{EE}$ as a control. These results suggest that there must be an optimal operating pressure for obtaining the maximal amount of chlorophyll $a$ from high-pressure homogenization, since some of the chlorophyll $a$ within Spirulina could be destroyed at the extremely high shear stress of approximately $50,000(1 / \mathrm{h})$ generated by 1370 bar of input pressure. This potential degradation of chlorophylls explains why the chlorophyll $a$ content of HP-3 was lower than that of HP-2 but was higher than that of EE or HP-1. This result is also supported by other research showing that the cell walls of Spirulina are not as rigid as those of plants [26]. In addition to this result, only a small yield of chlorophyll $a$ was achieved at a low pressure of 350 bar (HP-1), possibly because the cell walls of Spirulina were not completely broken at this low shear stress and consequently did not allow large amounts of chlorophyll to diffuse into the solvent in the relatively short extraction time. Therefore, a simple high-pressure homogenization process can greatly increase the extraction yield of chlorophyll $a$ by efficiently disrupting the structure of Spirulina under an optimal input pressure. When processed at 350 bar, many of the cells remained intact, which explains why the yield of chlorophyll $a$ was lower at that pressure than at 690 bar. Therefore, the results shown in these figures confirmed the results shown in Table 1, which indicated that there must be an optimal input pressure when employing high-pressure homogenization to obtain chlorophyll $a$ from Spirulina. In this work, 690 bar emerged as a preliminary optimal pressure, which easily released chlorophyll $a$ from the biomass within a very short time even at room temperature, when the intact chlorophyll $a$ content and neuroprotective effects of extracts were compared across three different levels of input pressures such as 350, 690, and 1370 bar. However, more exact optimal conditions should be determined with greater accuracy by optimizing many effective parameters of high-pressure homogenization in processing Spirulina sp. Other works observed similar effects of high-pressure homogenization, finding that it easily broke down the structures of the biomass [16,17]. These results were very interesting and constituted a starting point for applying this unique process to extract other components from natural resources. Our results concerning antioxidant activity strongly indicated that the HP extract had higher antioxidant activity than chlorophyll $a$ alone even at the same dosage, possibly due to additive effects of other components in the HP extract. By contrast, the EE extract showed lower antioxidant effects than $10 \mu \mathrm{g} / \mathrm{mL}$ of chlorophyll $a$ alone because the EE yield was not high enough for there to be $10 \mu \mathrm{g} / \mathrm{mL}$ of chlorophyll $a$ in the extract and there were not enough other bioactive components. These results demonstrated that the extract from a simple high-pressure homogenization had higher antioxidant activity than the EE extract or even chlorophyll $a$ alone, which meant that the HP extract was expected to show strong neuroprotective effects as well. The neuroprotection results also strongly indicated that chlorophyll $a$ must play an important role in protecting cell growth against damage by glutamate, since the HP extract contained higher amounts of chlorophyll $a$ than the ethanol extract did. Similar results concerning the neuroprotective effects of chlorophylls from plant sources were also reported in other works [23]; however, those mixed chlorophylls seemed to be less effective than chlorophyll $a$ in this work and were much less effective than the HP extract as well. For the protection of nerve cells, chlorophyll $a$ might be more efficacious than other chlorophylls. We can confidently conclude that the stronger effects of HP extract are attributable at least in part to higher amounts of chlorophyll $a$, but it is still controversial whether the difference can be explained entirely by chlorophyll $a$, since the HP extract contained other bioactive substances as well. Instead, it appears that the neuroprotective activity of HP was caused by additive effects of various biologically active substances in the extract, including but not limited to chlorophyll $a$, as already confirmed by the analysis of antioxidant activities [12,23]. 
This result confirmed other results showing that high antioxidant activity could be closely related to protection against oxidative stress, which resulted in neuroprotective activity $[27,28]$. The HP extract achieved higher reduction of ROS production than the same concentration of chlorophyll $a$ that existed in the HP, and it was even better than those of other extracts, such as $97.45 \%$ in Bozhougyiqi-tang and $97.41 \%$ in Nelumbo nucifera seed $[29,30]$. These results also supported the hypothesis that the extract from high-pressure homogenization was superior to chlorophyll $a$ alone or other extracts, possibly due to high amounts of various bioactive substances along with a high content of chlorophyll $a$ in the HP extract. The results of this work clearly demonstrated that the strong neuroprotective activity of the HP extract was caused mainly by additive effects, not chlorophyll $a$ alone, and that the high-pressure homogenization process can yield many biologically active components in quantities not achieved by conventional processes. Similar results from other works also support these findings [17]. Therefore, this work leads to the rational conclusion that an effective extraction process must be developed to obtain extracts with good biological activity, which can also help to reduce the complex purification process of crude extracts. In this work, the neuroprotective effects of chlorophyll $a$ were also confirmed for the first time, although mixtures of chlorophyll $a, b$, and $c$ or total chlorophylls from various biomass sources have shown several types of neuroprotective activity $[12,23,24]$. Moreover, this work clearly showed that the neuroprotective activity of the HP extract was caused mainly by increased antioxidant activity and consequent reduction of oxidative stress by antioxidant activity, with cascading protective effects on mouse hippocampal neuronal cells. However, more comprehensive in vivo and ex vivo experiments on the extracts from this unique process should also be conducted to better confirm the possibility of employing this process to easily upgrade the quality of extracts in various industrial fields.

\section{Conclusions}

This work demonstrated that the high-pressure homogenization process, which has been used mainly for mixing hydrophobic and hydrophilic components, could be employed to effectively break down the structure of S. platensis. First, this process showed the ability to greatly increase the extraction yield of chlorophyll $a$ and other bioactive substances using a simple and easily scaled-up method. Additionally, this unique extraction process was found to be very effective in extracting chlorophyll $a$ from Spirulina at a low temperature, which is beneficial because the major chlorophyll in Spirulina is the extremely heat-sensitive chlorophyll $a$. Therefore, the extract from this process showed very high antioxidant activity through the additive effects of large amounts of chlorophyll $a$ and other biologically active components in the extract, which effectively reduced oxidative stress in mouse hippocampal neuronal cells and consequently protected them from neuronal damage due to glutamate. It was also shown for the first time that chlorophyll $a$ had greater neuroprotective activity and efficacy than other chlorophylls from plant sources. Moreover, the crude extracts from a high-pressure extraction process had greater neuroprotective activity than chlorophyll $a$ alone in that chlorophyll $a$ was less efficacious than crude extract containing the same amounts of chlorophyll $a$, possibly due to the additive effects of other substances extracted by the HP process. In conclusion, these results clearly confirmed that the high neuroprotective effects of the HP extract were caused mainly by the additive efficacy of abundant intact chlorophyll $a$ and other bioactive components in the extract even at a low temperature. It was also shown that the neuroprotective activity of the extracts was strongly associated with high antioxidant activity. Therefore, the results of this work will be employed to expand the use of a nonthermal extraction process to obtain heat-sensitive components from natural resources.

Author Contributions: Woon Yong Choi carried out all of the experiments and Hyeon Yong Lee designed all of the experiments and drafted the manuscript. All authors read and approved the final manuscript.

Conflicts of Interest: The authors declare no conflict of interest. 


\section{References}

1. Khan, Z.; Bhadouria, P.; Bisen, P.S. Nutritional and therapeutic potential of Spirulina. Curr. Pharm. Biotechnol. 2005, 6, 373-379. [CrossRef] [PubMed]

2. Kay, R.A. Microalgae as food and supplement. Crit. Rev. Food Sci. Nutr. 1991, 30, 555-783. [CrossRef] [PubMed]

3. Gad, A.S.; Khadrawy, Y.A.; El-Nekeety, A.A.; Mohamed, S.R.; Hassan, N.S.; Abdel-Wahhab, M.A. Antioxidant activity and hepatoprotective effects of whey protein and Spirulina in rats. Nutrition 2011, 27, 582-589. [CrossRef] [PubMed]

4. Lee, Y.J.; Kim, S.H.; Kim, J.S.; Han, J.A.; Seo, H.J.; Lim, H.J.; Choi, S.Y. Studies on Simultaneous Determination of Chlorophyll $a$ and $b$, Pheophorbide $a$, and $\beta$-Carotene in Chlorella and Spirulina Products. J. Food Hyg. Saf. 2005, 20, 141-146.

5. Yamada, T.; Sakaguchi, K. Comparative studies on Chlorella cell walls: Induction of protoplast formation. Arch. Microbiol. 1982, 132, 10-13. [CrossRef]

6. Silveira, S.T.; Burkert, J.F.M.; Costa, J.A.V.; Burkert, C.A.V.; Kalil, S.J. Optimization of phycocyanin extraction from Spirulina platensis using factorial design. Bioresour. Technol. 2007, 98, 1629-1634. [CrossRef] [PubMed]

7. Hosikian, A.; Lim, S.; Halim, R.; Danquah, M.K. Chlorophyll extraction from microalgae: A review on the process engineering aspects. Int. J. Chem. Eng. 2010, 2010, 1-11. [CrossRef]

8. Hosseini, S.M.; Shahbazizadeh, S.; Khosravi-Darani, K.; Mozafari, M.R. Spirulina paltensis: Food and Function. Curr. Nutr. Food Sci. 2013, 9, 189-193. [CrossRef]

9. Lee, J.C.; Hou, M.F.; Huang, H.W.; Chang, F.R.; Yeh, C.C.; Tang, J.Y.; Chang, H.W. Marine algal natural products with anti-oxidative, anti-inflammatory, and anti-cancer properties. Cancer Cell. Int. 2013, 13, 55-61. [CrossRef] [PubMed]

10. Danesi, E.D.G.; Rangel-Yagui, C.O.; Carvalho, J.C.M.; Sato, S. Effect of reducing the light intensity on the growth and production of chlorophyll by Spirulina platensis. Biomass Bioenergy 2004, 26, 329-335. [CrossRef]

11. Bhat, S.R. Chlorophyll: The wonder pigment. Sci. Rep. 2005, 42, 29-32.

12. Lanfer-Marquez, U.M.; Barros, R.M.C.; Sinnecker, P. Antioxidant activity of chlorophylls and their derivatives. Food Res. Int. 2005, 38, 885-891. [CrossRef]

13. Furuki, T.; Maeda, S.; Imajo, S.; Hiroi, T.; Amaya, T.; Hirokawa, T.; Ito, K.; Nozawa, H. Rapid and selective extraction of phycocyanin from Spirulina platensis with ultrasonic cell disruption. J. Appl. Psychol. 2003, 15, 319-324. [CrossRef]

14. Leonelli, C.; Mason, T.J. Microwave and ultrasonic processing: Now a realistic option for industry. Chem. Eng. Process 2010, 49, 885-900. [CrossRef]

15. Fernandez-Avila, C.; Trujillo, A.J. Enhanced stability of emulsions treated by Ultra-High Pressure Homogenization for delivering conjugated linoleic acid in Caco-2 cells. Food. Hydrocoll. 2017, 71, 271-281. [CrossRef]

16. Yap, B.H.J.; Dumsday, G.J.; Scales, P.J.; Martin, G.J.O. Energy evaluation of algal cell disruption by high pressure homogenization. Bioresour. Technol. 2015, 184, 280-285. [CrossRef] [PubMed]

17. Samarasinghe, N.; Fernando, S.; Lacey, R.; Faulkner, W.B. Algal cell rupture using high pressure homogenization as a prelude to oil extraction. Renew. Energy 2012, 48, 300-308. [CrossRef]

18. Williams, S.T.; Davies, F.L. Use of a Scanning Electron Microscope for the Examination of Actinomycetes. Microbiology 1967, 48, 171-177. [CrossRef] [PubMed]

19. Petrović, S.M.; Savić, S.R.; Marković, D.Z.; Petronijević, Ž.B. In vitro studies of temperature and pH influence on chlorophyll degradation by horseradish peroxidase: Spectroscopic and HPLC studies. Hem. Ind. 2014, 68, 233-239. [CrossRef]

20. Dietz, B.M.; Kang, Y.H.; Liu, G.; Eggler, A.L.; Yao, P.; Chadwick, L.R.; Pauli, G.F.; Farnsworth, N.R.; Mesecar, A.D.; Breemen, R.B.; et al. Xanthohumol isolated from Humulus lupulus inhibits menadione-induced DNA damage through induction of quinone reductase. Chem. Res. Toxicol. 2005, 18, 1296-1305. [CrossRef] [PubMed]

21. Elmlinger, M.W.; Kriebel, M.; Ziegler, D. Neuroprotective and Anti-Oxidative Effects of the Hemodialysate Actovegin on Primary Rat Neurons in Vitro. Neuromol. Med. 2011, 13, 266-274. [CrossRef] [PubMed]

22. Lee, J.; Weon, J.B.; Ma, C.J. Neuroprotective activity of phytosterols isolated from Artemisia apiacea. Korean J. Pharmacogn. 2014, 45, 214-219. 
23. Rehni, A.K.; Pantlya, H.S.; Shri, R.; Singh, M. Effect of chlorophyll and aqueous extracts of Bacopa monniera and Valeriana wallichii on ischaemia and reperfusion-induced cerebral injury in mice. Indian J. Exp. Biol. 2007, 45, 764-769. [PubMed]

24. Chernomorsky, S.A.; Segelman, A.B. Biological activities of chlorophyll derivatives. N. J. Med. 1988, 85, 669-673.

25. Rangel-Yagui, C.O.; Danesi, E.D.G.; Carvalho, J.C.M.; Sato, S. Chlorophyll production from Spirulina platensis: Cultivation with urea addition by fed-batch process. Bioresour. Technol. 2004, 92, 133-141. [CrossRef]

26. Safi, C.; Charton, M.; Pignolet, O.; Silvestre, F.; Vaca-Garcia, C.; Pontalier, P.Y. Influence of microalgae cell wall characteristics on protein extractability and determination of nitrogen-to-protein conversion factors. J. Appl. Phycol. 2013, 25, 523-529. [CrossRef]

27. Ahmed, I.; John, A.; Vijayasarathy, C.; Robin, M.A.; Raza, H. Differential modulation of growth and glutathione metabolism in cultured rat astrocytes by 4-hydroxynonenal and green tea polyphenol, epigallocatechin-3-gallate. Neurotoxicology 2002, 23, 289-300. [CrossRef]

28. Armstrong, J.S.; Jones, D.P. Glutathione depletion enforces the mitochondrial permeability transition and causes cell death in Bcl-2 overexpressing HL60 cells. FASEB J. 2002, 16, 1263-1265. [CrossRef] [PubMed]

29. Weon, J.B.; Lee, B.; Yun, B.R.; Lee, J.; Ma, J.Y.; Ma, C.J. Neuroprotective and cognitive enhancing activity of the fermented Bozhougyiqi-Tang. Pharmacogn. Mag. 2014, 10, 249-255. [CrossRef]

30. Kim, E.S.; Weon, J.B.; Yun, B.R.; Lee, J.; Eom, M.R.; Oh, K.H.; Ma, C.J. Cognitive Enhancing and Neuroprotective Effect of the Embryo of the Nelumbo nucifera Seed. Evid. Based Complement. Altern. Med. 2014, 2014. [CrossRef] [PubMed]

(C) 2018 by the authors. Licensee MDPI, Basel, Switzerland. This article is an open access article distributed under the terms and conditions of the Creative Commons Attribution (CC BY) license (http:/ / creativecommons.org/licenses/by/4.0/). 